\title{
TESTS OF PROTOTYPE PCM 'SAILS' FOR OFFICE COOLING
}

\author{
Gideon Susman $^{\mathrm{a}, \mathrm{b}}$, , Zahir Dehouche ${ }^{\mathrm{a}}$, Tanawat Cheechern ${ }^{\mathrm{a}}$ and Salmaan Craig ${ }^{\mathrm{b}}$
}

${ }^{a}$ School of Engineering and Design, Brunel University, Uxbridge, Middlesex, UB8 3PH, UK

${ }^{\mathrm{b}}$ Buro Happold Engineers, 17, Newman Street, London, W1T 1PD

* Corresponding author. Tel.: +44 2079279700; fax.: +44 8707874145. Email address: gideon.susman@burohappold.com

\begin{abstract}
PCM modules, constructed from a paraffin/LDPE composite, were tested in an occupied London office, in summer. Design variations tested the effect on heat transfer of a black paint or aluminium surface, the effect of different phase transition zones and the effect of discharging heat inside or outside. The modules' temperatures were monitored along with air flow rate, air temperature and globe temperature. Their small size meant any effect on room temperature was negligible.

Using DSC measurements of the PCMs' thermophysical properties, in conjunction with the environmental measurements, semi-empirical models of the modules were constructed in FLUENT using an enthalpy porosity formulation to model phase change. Good validation was obtained using the temperature measurements with notable divergence noted when maximum liquid fraction was reached. The models were validated by the temperature measurements and used to generate mean liquid fraction and surface heat transfer rate profiles for performance comparisons.

The broad phase transition zones of the PCMs results in wasted latent heat capacity. Black modules transfer heat and exhaust latent storage capacity significantly quicker than aluminium modules, due to radiant exchange. Discharging heat outside leads to an increase in thermal storage capacity and a higher rate of heat absorption.
\end{abstract}


Keywords: Buildings, Cooling, PCM, Sails, Energy 


\section{NOMENCLATURE}

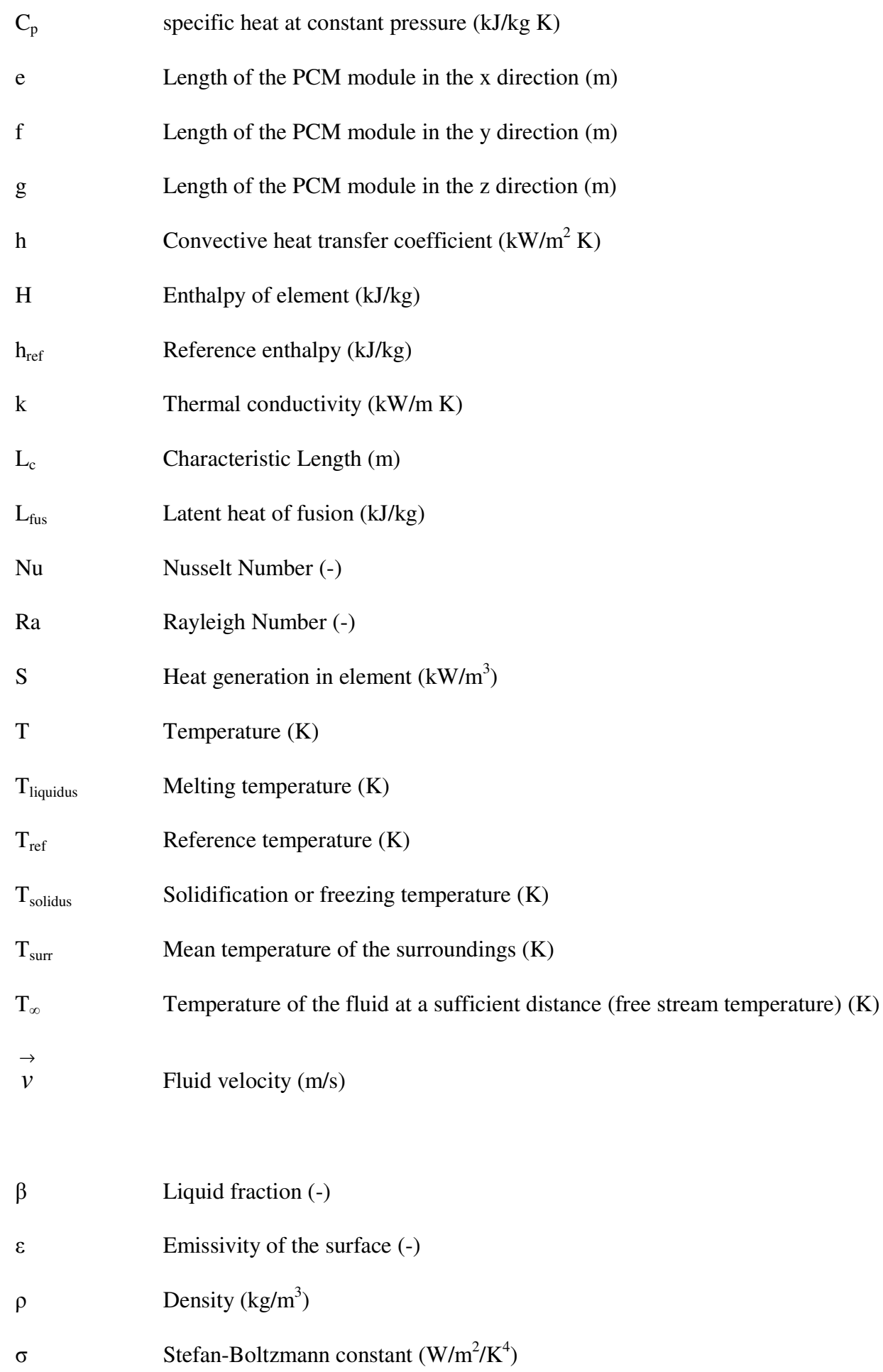


A26,Al,EC Externally-cooled, aluminium-covered, A26 module.

A22,B1,EC Externally-cooled, black-painted, A22 module.

A22,B1,IC Internally-cooled, black-painted, A22 module.

\section{INTRODUCTION}

Research and development of passive PCM technologies has tended to focus on fabric incorporation of PCM elements - commonly wallboards. Performance is often assessed in terms of the internal temperature reduction, as in the research conducted by Scalat et al. [1], Schossig et al. [2], Ahmad et al. [3], Kuznik and Virgone [4] and Castell et al. [5]. Optimisation of characteristics has been investigated by, for example, Kuznik et al. [6], in terms of wall board thickness, and ideal thermophysical properties by Zhang et al. [7]. Commercially available products have emerged such as DuPont Energain [8]. Examples of PCM incorporation into concrete may be found in Hadjeva et al.'s study into stabilising shape through combination with concrete [9] and Cabeza et al. [10].

Hawes et al. [11] identify several reasons why wallboards and concrete blocks are selected for passive temperature control, such as the ease with which they can be installed by tradesmen with conventional skills and the fact that production and marketing can be conducted with existing facilities. The aim with that approach is for products to fit into existing construction processes but the disadvantage is that the heat transfer rate and thermal capacity are necessarily limited by a limited $u s e f u l$ surface area and depth of heat penetration. A further issue is the potential inability to sufficiently reject heat at night due to elevated night time ambient temperatures.

There is an opportunity to develop PCM elements that are not incorporated into the building fabric to increase the surface area and available capacity. This may be done through the creation of 'Sails', units designed for location below the ceiling in an occupied space. Sail designs have been developed by companies such as S\&P Coil Products [12], where it is understood that the increased surface area creates increased convective heat transfer rates. Thermal fabric element manufacturer, Ilkazell, have developed the Ilkatherm panel [13] that incorporates PCM and may be employed as a cooling sail. However this does not increase the surface area of the system since only the bottom surface is exposed. 
In this work prototype PCM Sails were constructed from commercially available paraffin/low-densitypolyethylene (LDPE) composites and positioned below the ceiling of an occupied office space. This was done to obtain environmental data for the validation of semi-empirical models of the Sail modules, whose internal temperature was monitored. It also allowed the external discharge of heat to take place on a typical central London rooftop, which meant the modules would cool to the level that would be expected in a full-scale installation. The cooling effect of each module can be inferred by the heat absorbed. The modules were intended to absorb excess room heat during the daytime, through the melting of the contained paraffin, and then discharge this heat at night, through the freezing of the paraffin. Four modules were constructed to test three design variations:

The first variation was in the surface of the modules: aluminium foil and tape or aluminium foil and tape, sprayed with matt black paint. The black modules were intended to interact radiantly (as well as convectively) with the surroundings during both charge and discharge; the aluminium modules were only intended to interact convectively.

The second variation was in the choice of PCM itself. Both were paraffins but one had a manufacturerquoted transition zone of $22^{\circ} \mathrm{C}$ and the other of $26^{\circ} \mathrm{C}$, known as A22 and A26, respectively [14]. A22 was intended to begin transferring heat faster at lower temperatures, with A26 reacting only at higher temperatures. The anticipated result was that, assuming full freezing occurred the previous night, during days in which the dry bulb air temperature reached a maximum between $22^{\circ} \mathrm{C}$ and $26^{\circ} \mathrm{C}$, only A22 would melt, while A26 would remain fully frozen.

The third variation was in the location for cooling. Every evening three modules were transported to a roof-top rig to discharge their heat while one remained inside to cool. Transporting PCM modules outside presents a mechanical engineering challenge but has the advantage of greater contact with night time heat sinks. As an example, cross-envelope transport could be realised through a rotating rooflight. PCM Sail units would be attached to the underside of the rooflight to effect cooling during the daytime. At night, the rooflight elements would rotate $180^{\circ}$, thus exposing the PCM Sails to the night time sky and air.

The modules tested were an externally-cooled, aluminium-covered, A22 module (A22,A1,EC), an externally-cooled, aluminium-covered, A26 module (A26,A1,EC), an externally-cooled, black, A22 module (A22,B1,EC), module and an internally-cooled, black, A22 module (A22,B1,IC). Each variation is 
manifested in at least two modules, which are identical in every other respect, to allow reliable comparisons.

\section{EXPERIMENTAL METHOD}

\subsection{Module Construction}

All modules were constructed from four $150 \mathrm{~mm}^{2}$ paraffin/LDPE composite tiles, covered with aluminium foil and held firmly together with aluminium tape and nylon chord. (The LDPE stabilized the shape of the paraffin upon melting.)

Type-k thermocouples were placed at seven locations throughout the body of the module. Five between the layers and two buried in the top and bottom surfaces - see Fig. 1.

\subsection{In Situ Monitoring}

During daytime the modules were hung from a rig $2.5 \mathrm{~m}$ above the ground: the height at which full scale systems would be located (see Fig. 2). The thermocouples were connected to wall-mounted data loggers, which in turn were connected to a laptop for recording temperature at single minute intervals. This allowed near constant recording over several days without disturbance to occupants. Due to their small size, it was assumed that no detectable effect on the room temperature would occur.

Two hobo data loggers were hung from either end of the rig to record the dry bulb temperature, taken to be the mean, every three minutes. This also verified that the air temperature around the modules was near uniform. A globe thermometer was also hung from the rig and recorded at minute intervals.

At around 8:00pm the A22,B1,IC module remained in its position to discharge, while the rest were hung from a roof-top rig (see Fig. 3.). The thermocouples in the external modules were connected to internally located loggers and a laptop, for monitoring throughout the night. A tinytag logger was hung from the external rig to record the external air temperature at three minute intervals. 
At around 7:00am the outside cooling modules were transferred from the external rig to the internal rig. This procedure took around 30 to 50 minutes, during which time data logging ceased. The reverse procedure took the same time. Maximum and average wind speeds, as well as dry bulb temperature, were recorded at the time of each transfer.

\subsection{CFD Modelling, Validation and Generation of Parameter Profiles}

The in-situ measurements were used in conjunction with differential scanning calorimetry (DSC) measurements of thermophysical properties to produce semi-empirical CFD models of the modules with the solidification/melting solver in FLUENT. This uses an enthalpy porosity formulation to model the melting and solidification of the PCM. This means that the liquid front is not tracked explicitly. Instead an enthalpy balance,

$$
\frac{\partial}{\partial t}(\rho H)+\nabla(\rho \vec{\rho} H)=\nabla(k \nabla T) \pm S,
$$

in which

$$
\mathrm{H}=\mathrm{h}_{\mathrm{ref}}+\int_{T_{\text {ref }}}^{T} C_{p} d T+\beta \mathrm{L}_{\text {fus }}
$$

is used to compute the liquid fraction, $\beta$, where,

$$
\begin{gathered}
\beta=0 \text { if } \mathrm{T}<\mathrm{T}_{\text {solidus }} \\
\beta=1 \text { if } \mathrm{T}>\mathrm{T}_{\text {liquidus }} \\
\beta=\frac{T-T_{\text {solidus }}}{T_{\text {liquidus }}-T_{\text {solidus }}} \text { if } \mathrm{T}_{\text {solidus }}<\mathrm{T}<\mathrm{T}_{\text {liquidus }},
\end{gathered}
$$


at each time step [15].

FLUENT performs iterations between equations 1 and 2 in order to find the temperature in each element [15]. Since the LDPE stabilises the paraffin's shape upon melting, all particles have permanent zero velocity. In addition, no heat generation occurs and so the associated terms go to zero and drop out of Eq. (1):

$$
\frac{\partial(\rho H)}{\partial t}=\nabla(k \nabla T)
$$

Substituting for H (Eq. (2)), Eq. (5) results:

$$
\left[\rho C_{p}+\frac{\rho L}{\left(T_{\text {liquidus }}-T_{\text {solidus })}\right.}\right] \frac{\partial T}{\partial t}=\nabla(k \nabla T)
$$

The thermophysical properties of the PCMs are shown in Table 1 and Fig.s 4 and 5. Here "Melt start temp" refers to the temperature at which melting begins, as the temperature of the substance is increased, found through analysis of DSC data. "Melt finish temperature" refers to the temperature at which melting ceases. "Freeze start temp" and "Freeze finish temp" equivalently refer to start and finish temperatures for freezing, off-set from the melting temperatures because of under-cooling.

During charge periods $\mathrm{T}_{\text {solidus }}$ is taken to be equal to "Melt start temp" and $\mathrm{T}_{\text {liquidus }}$ is taken to equal "Melt finish temp", for that material. FLUENT models the sensible heating and melting of the material as a step function, illustrated in Fig.s 4 and 5.

FLUENT read the boundary conditions as shown in Eq.s (6), (7), (8) and (9):

For heating the modules: $\quad \forall t, \mathrm{x}=0, \quad-k \frac{\partial T}{\partial x}=\mathrm{h}\left(\mathrm{T}_{\infty}-\mathrm{T}\right)+\varepsilon \sigma\left(\mathrm{T}_{\text {surr }}^{4}-\mathrm{T}^{4}\right)$. 


$$
\forall t, \mathrm{x}=\mathrm{e}, \quad-k \frac{\partial T}{\partial x}=\mathrm{h}\left(\mathrm{T}_{\infty}-\mathrm{T}\right)+\varepsilon \sigma\left(\mathrm{T}_{\text {surr }}^{4}-\mathrm{T}^{4}\right)
$$

For cooling the modules: $\quad \forall t, \mathrm{x}=0, \quad k \frac{\partial T}{\partial x}=\mathrm{h}\left(\mathrm{T}-\mathrm{T}_{\infty}\right)+\varepsilon \sigma\left(\mathrm{T}^{4}-\mathrm{T}_{\text {surr }}{ }^{4}\right)$.

$$
\forall t, \mathrm{x}=\mathrm{e}, \quad k \frac{\partial T}{\partial x}=\mathrm{h}\left(\mathrm{T}-\mathrm{T}_{\infty}\right)+\varepsilon \sigma\left(\mathrm{T}^{4}-\mathrm{T}_{\text {surr }}^{4}\right)
$$

In Eq.s (6) and (7) the emissivity, $\varepsilon$, is taken to be equivalent to the absorptance of the surface. These conditions apply equally in the $\mathrm{y}$ and $\mathrm{z}$ directions, exchanging $\mathrm{x}$ for $\mathrm{y}$ or $\mathrm{z}$ and e for $\mathrm{f}$ or $\mathrm{g}$, respectively.

For the black modules, $\mathrm{T}_{\text {surr }}$ was taken to equal the recorded globe temperature and an emissivity of 0.98 was used [16].The aluminium modules were assumed to only interact convectively with the environment and so had an emissivity of zero. A convective heat transfer coefficient was calculated for all surfaces individually using Eq. (10):

$$
\mathrm{Nu}=\frac{h L_{c}}{k}
$$

Characteristic lengths of 0.15 and 0.035 were used for the top/bottom and side surfaces, respectively. Nusselt numbers were calculated using Eq.s (11), (12) and (13) for the bottom, top and side surfaces, respectively.

$$
\begin{gathered}
\mathrm{Nu}=0.54 \mathrm{Ra}^{1 / 4} \\
\mathrm{Nu}=0.27 \mathrm{Ra}^{1 / 4} \\
\mathrm{Nu}=\left\{0.825+\frac{0.387 R a^{1 / 6}}{\left(1+(0.492 / \mathrm{Pr})^{9 / 16}\right)^{8 / 27}}\right\}^{2}
\end{gathered}
$$


A weighted average of $5.00 \mathrm{~W} / \mathrm{m}^{2} / \mathrm{K}$ was found and applied to all surfaces equally; however validation was improved by applying heat transfer coefficients in the range $7-9 \mathrm{~W} / \mathrm{m}^{2} / \mathrm{K}$. These values are broadly consistent with converted surface resistances from ASHRAE: $6.25 \mathrm{~W} / \mathrm{m}^{2} / \mathrm{K}$ and $8.33 \mathrm{~W} / \mathrm{m}^{2} / \mathrm{K}$ for downward facing horizontal and vertical surfaces, respectively [17].

Over the course of each charge simulation the free stream temperature was altered every 50 minutes to reflect the fluctuation in dry bulb temperature in the room. For the black modules this also applied to the globe temperature. The input convective heat transfer coefficient remained constant during this time. The average of all thermocouple temperatures at the beginning of each charge period was taken to be the uniform temperature of a given module at the start of any charge simulation. Validation was achieved by comparison of measured thermocouple temperatures and the temperatures found at corresponding locations in the corresponding CFD models - see Fig. 6.

It was important to validate the models to ensure that the generated profiles of average liquid fraction and total surface heat transfer rate could be taken to be true. The profiles were then used for performance comparisons.

The heat transfer rate profiles had a misleading number of sharp peaks resulting from the periodic changes in air and globe temperatures. The curve was smoothed out by taking the centrally occurring heat transfer values for each sub-period and disregarding the rest of the data.

\section{RESULTS}

\subsection{Validation}

Fig. 7. shows the temperature and liquid fraction contours for the A22,A1,EC module at three stages in the charging process. The rise in both parameters can be seen to start from the corners and edges of the module. At 450 minutes the module has just achieved a liquid fraction of 1, when no region is below $22.44^{\circ} \mathrm{C}$.

Validation curves for thermocouples A, B, C and D (see Fig.s 1 or 6) are presented. In most cases good validation of the models has been obtained, with some notable deviations. Fig. 8. shows the modeled and measured temperature profile of thermocouples in the A26,A1,EC module. A very close correlation 
may be observed. It is significant that the module's temperature range is almost entirely between the melt onset and melt finish temperatures of the A26 PCM. The curve therefore indicates a simultaneous gain in sensible and latent heat. This contrasts with the curve in Fig. 9, for the A22,Al,EC module, in which

thermocouples B, C and D display good correspondence until the material reaches $\mathrm{T}_{\text {liquidus. }}$. Here the temperature immediately rises more rapidly and deviates a maximum $1.0^{\circ} \mathrm{C}$ from the measured values.

This is because the model assumes a simple step function for the variation in heat flow to/from each element, rather than a smooth curve, as indicated in Fig. 5. The limitation of the FLUENT

solidification/melting solver is the transition between wholly sensible and partially latent heating/cooling processes.

Fig. 10 shows curves for the A22,B1,EC module. Good correlation is observed and the same sharp rise as seen in Fig. 9 is observed when the model reaches $\mathrm{T}_{\text {liquidus }}$. The model curves then peak and fall at an earlier time and lower temperature than the actual module. This is most likely due to an additional localised radiant heat source acting upon the module, direct sunlight being a strong possibility as the module had a good view of the window.

Fig.11. shows good validation of the A22,B1,IC model. Deviations are generally less extreme for the module cooled indoors because the air temperature variation is lower.

\subsection{Average Liquid Fraction and Surface Heat Transfer Rate Profiles}

Profiles have been generated for a single charge period, from 8:08am to 20:30pm. The air and globe temperatures for this period are displayed in Fig. 12. In general the results are best understood through comparison of two identical modules that differ in one respect - cooling location, surface material or PCM type. All modules were heated by the internal environment and so melted, at differing rates, over the course of the day.

Fig. 13 shows the average liquid fraction profiles for the four panels. The A22,B1,IC module was already $88 \%$ melted at the start of the period, compared with $56 \%$ for the equivalent externally cooled module, A22,B1,EC. This indicates that the internally cooled module was unable to sufficiently reject heat during the previous night. Outside, a large amount of rain had fallen and temperatures had dropped to a minimum of $14.5^{\circ} \mathrm{C}$, with maximum recorded wind speeds of 1.3 and 0.7 measured at 8:30pm and 
7:20am, respectively. All this contributed to the higher heat rejection rate achieved by the externally cooled module. By contrast, no detectable air flow was measured around the internally cooled module and the temperature only dropped to a minimum of $19.8^{\circ} \mathrm{C}$. This is because the room experiences a low ventilation rate at night, due to windows being closed for security reasons. In addition, significant heat gains resulted from eighteen computers, three printers and a refrigerator. At 11:42am the internally cooled module has completely melted and at $12: 47 \mathrm{pm}$ so has the externally cooled module - i.e. the liquid fractions reach a value of one. After this, only sensible heating occurs.

The A22,Al,EC module was $41 \%$ melted at the start of the period; $15 \%$ lower than its black counterpart, A22,B1,EC. However, this difference is not due to the aluminium module achieving a higher heat transfer rate the previous night. It is due to the extremely rapid absorption of heat by the black module during the time that the modules were brought inside and set up for internal monitoring. This is supported by the high heat transfer rate seen in the black module at the beginning of the charge period (see Fig. 14) and the fact that the black module had achieved a lower temperature than the aluminium module at the end of the cooling period; $15.7^{\circ} \mathrm{C}$ and $17.6^{\circ} \mathrm{C}$, respectively. The A22,Al,EC module became fully melted at $16: 15 \mathrm{pm}$.

The partially molten state of the A22 modules at the start of the period is seen as a disadvantage of the material. At this time the surface temperatures (the warmest part of the modules) of the A22,A1,EC and A22,B1,EC modules are $16.7^{\circ} \mathrm{C}$ and $18.6^{\circ} \mathrm{C}$, respectively. The modules are significantly melted at temperatures below the thermal comfort zone (taken to be $20^{\circ} \mathrm{C}-24^{\circ} \mathrm{C}$ ). This behaviour can be explained with reference to Fig. 5 which shows the DSC results for the A22/LDPE composite. Here the substance is shown to start to melt at $11.22{ }^{\circ} \mathrm{C}$ (even lower in fact.) The portion that melts at temperatures below the thermal comfort zone either decreases the possibility of effective heat rejection at night (as in this case) or removes heat unnecessarily from the room. In both cases valuable storage capacity is not available for cooling. To minimize volume and weight of PCM, a material with a similar energy density and a transition zone more closely aligned to the thermal comfort zone, should be sought.

This problem applies similarly to A26 but here the excess capacity is found largely above the thermal comfort zone with the material becoming fully melted at $27.28^{\circ} \mathrm{C}-$ see Fig. 4 . The A26,Al,EC module differed from it counterpart A22,A1,EC module (and the other modules) in that it was completely solid at the start of the discharge period due to its having a higher melt temperature. At the end of the period it is 
only $70 \%$ melted. The maximum room temperature was $25.56{ }^{\circ} \mathrm{C}$, not high enough to fully melt the A26 despite being above the thermal comfort zone.

Fig. 14 shows the surface heat transfer rates for the same charge period and modules. The general design conflict to be noted here is that as the temperature rises throughout the day, the cooling capacity of the modules fall. All start at a maximum and fall continuously due to increasing surface temperatures, apart from the A22,B1,IC module. At 8:32 this module is transferring heat at $3.25 \mathrm{~W} / \mathrm{m}^{2}$ rising to 12.22 $\mathrm{W} / \mathrm{m}^{2}$ at $10: 12$ due to increasing globe and air temperatures. This is only possible because it begins the period with such a small temperature difference with its environment. The higher heat transfer rates achieved by the externally cooled modules are more desirable for a cooling system, with values of 37.33, 27.93 and $34.47 \mathrm{~W} / \mathrm{m}^{2}$ achieved initially for the A22,B1,EC, the A22,A1,EC and the A26,A1,EC modules, respectively. The A22,Al,EC exhausts its capacity so quickly that from 14:22 onwards it is transferring heat at the same rate as its internally cooled counterpart. This rapid heat transfer is why it completely melts so early. It should be noted, however, that a full scale installation would hold the internal temperature down and so produce a more level heat flux over time.

The A22,A1,EC module starts at a lower heat flux than its black counterpart, A22,B1,EC, but by 11:52 is transferring heat at higher rate because of its lower temperature. The higher heat flux is due to the black module's radiant interaction with the environment. The aluminum module has negligible radiant interaction. Because the black module heats up quicker, its heat exchange rate falls quicker due to a lower temperature difference between the surface and the surroundings. In this instance the aluminium module appears to function more favourably as it maintains a higher heat flux for most of the period; particularly during times of peak temperature.

The A26 module maintains the most steady heat flux because of its negligible radiant interaction with the environment and the fact that it never exhausts its latent heat capacity. In towards the end of the day it is transferring heat faster than its A22 counterpart due to the A22,A1,EC exhausting all of its latent heat capacity, causing it to hasten towards thermal equilibrium with the room.

\section{CONCLUSIONS}


The modeling method proved effective with good validation obtained in most cases; however a limitation in the FLUENT solver was revealed when significant deviations were observed between model and reality when the model reaches an average liquid fraction of 1.

The generated average liquid fraction profiles and total surface heat transfer rates provide a clear basis for comparison of module performance and several conclusions were reached:

The A22 material was shown to melt at excessively low temperatures, causing much of its thermal storage capacity to either not be accessed, in cases when not all heat can be rejected at night, or exhausted unnecessarily by removing heat from the room at low temperatures. This problem exists in the opposite way for the A26 material because it cannot fully melt, even at temperatures above the comfort zone.

The A22,B1,EC module transfers heat and exhausts its latent storage capacity quicker than the equivalent aluminium-encapsulated module, A22,A1,EC, which maintains a more steady heat transfer rate, showing radiant interaction to be a significant element in the heat transfer to the modules.

The A22,B1,IC transferred far less heat and became fully melted earlier than its externally cooled counterpart. This highlights an opportunity to greatly increase heat rejection through the transport of PCM modules outside at night and highlights the need for effective ventilation, should the modules remain inside

All modules' surface heat fluxes declined significantly, reaching zero $\mathrm{W} / \mathrm{m}^{2}$ before the end of the charging period. This must be avoided in a full scale system to ensure cooling is achieved throughout the day.

Continuing work could look at simulating full-scale Passive PCM Sail systems which promote radiant heat transfer, use PCM with a phase transition zone more closely aligned to the thermal comfort zone and can be efficiently transported outside for cooling at night.

\section{ACKNOWLEDGEMENTS}

The authors would like to express their gratitude to Daniel Cash, of Buro Happold Building Services, for his invaluable design input and assistance with module construction and experimental set-up. 


\section{REFERENCES}

[1] SCALAT, S., BANU, D., HAWES, D., PARIS, J., HAGHIGHATA, F. and FELDMAN, D., 1996.

Full scale thermal testing of latent heat storage in wallboard. solar Energy Materials and Solar Cells, 44, 49-61.

[2] SCHOSSIG, P., HENNING, H.-., GSCHWANDER, S. and HAUSSMANN, T., 2005. Microencapsulated phase-change materials integrated into construction materials. Solar Energy Materials and Solar Cells, 89(2-3), 297-306.

[3] AHMAD, M., BONTEMPS, A., SALLEE, H. and QUENARD, D., 2006. Thermal testing and numerical simulation of a prototype cell using light wallboards coupling vacuum isolation panels and phase change material. Energy and Buildings, 38, 673-681.

[4] KUZNIK, F. and VIRGONE, J., 2009. Experimental assessment of a phase change material for wall building use. Applied Energy, 86(10), 2038-2046.

[5] CASTEll, A., MARTORELL, I., MEDRANO, M., PÉREZ, G. and CABEZA, L.F., 2010. Experimental study of using PCM in brick constructive solutions for passive cooling. Energy and Buildings, 42(4), 534-540.

[6] KUZNIK, F., VIRGONE, J. and NOEL, J., 2008. Optimization of a phase change material wallboard for building use. Applied Thermal Engineering, 28(11-12), 1291-1298.

[7] ZHANG, Y., LIN, K., ZHANG, Q. and DI, H., 2006/10. Ideal thermophysical properties for freecooling (or heating) buildings with constant thermal physical property material. Energy and Buildings, 38(10), 1164-1170

[8] DUPONT, 2007, 2007-last update, DuPont Energain [Homepage of DuPont], [Online]. Available: http://www2.dupont.com/Energain/en_GB/ [04/29, 2007].

[9] HADJIEVA, M., STOYKOV, R. and FILIPOVA, T., 2000/1/2. Composite salt-hydrate concrete system for building energy storage. Renewable Energy, 19(1-2), 111-115.

[10] CABEZA, L.F., CASTELlÓN, C., NOGUÉS, M., MEDRANO, M., LEPPERS, R. and ZUBILLAGA, O., 2007. Use of microencapsulated PCM in concrete walls for energy savings. Energy and Buildings, 39(2), 113-119.

[11] HAWES, D.W., FELDMAN, D. and BANU, D., 1993. Latent heat storage in building materials. Energy and Buildings, 20, 77-86.

[12] S\&P COIL PRODUCTS, 2010-last update, Thermasail radiant conditioning sails [Homepage of S\&P Coil Products Ltd], [Online]. Available: http://www.buildingdesign.co.uk/arch-technical/spc-t/thermasailradiant-conditioning-sails-heating-cooling-operations.htm [07/10, 2010].

[13] ILKATHERM, 2010-last update, Ilkatherm Ceiling [Homepage of Ilkatherm Isoliertechnik GmbH], [Online]. Available: http://www.ilkazell.de/en_baudecke.php [02/21, 2010].

[14] A22 and A26 PlusICE Organic PCMs, Available from: Phase Change Material Products Limited:

http://www.pcmproducts.net/home.htm. 
[15] V.R. Voller, An overview of numerical methods for solving phase change problems, in: W.J.

Minkowycz, E.M. Sparrow (eds) Advances in Numerical Heat Transfer, Vol. 9 (1st edn), Taylor \&

Francis, Abingdon, 1996.

[16] Y.A. Cengel, Heat transfer: A practical approach. (2nd edn), McGraw-Hill, New York, 2003.

[17] BAGHERI, H.M., BANSAL, P.K., COAD, W.J., FULK, K.M., HITTLE, D.C., WELLS III, J.W. and YUILL, D.P., 2009. 2009 ASHRAE Handbook: Fundementals. SI edn. Atlanta: ASHRAE. 


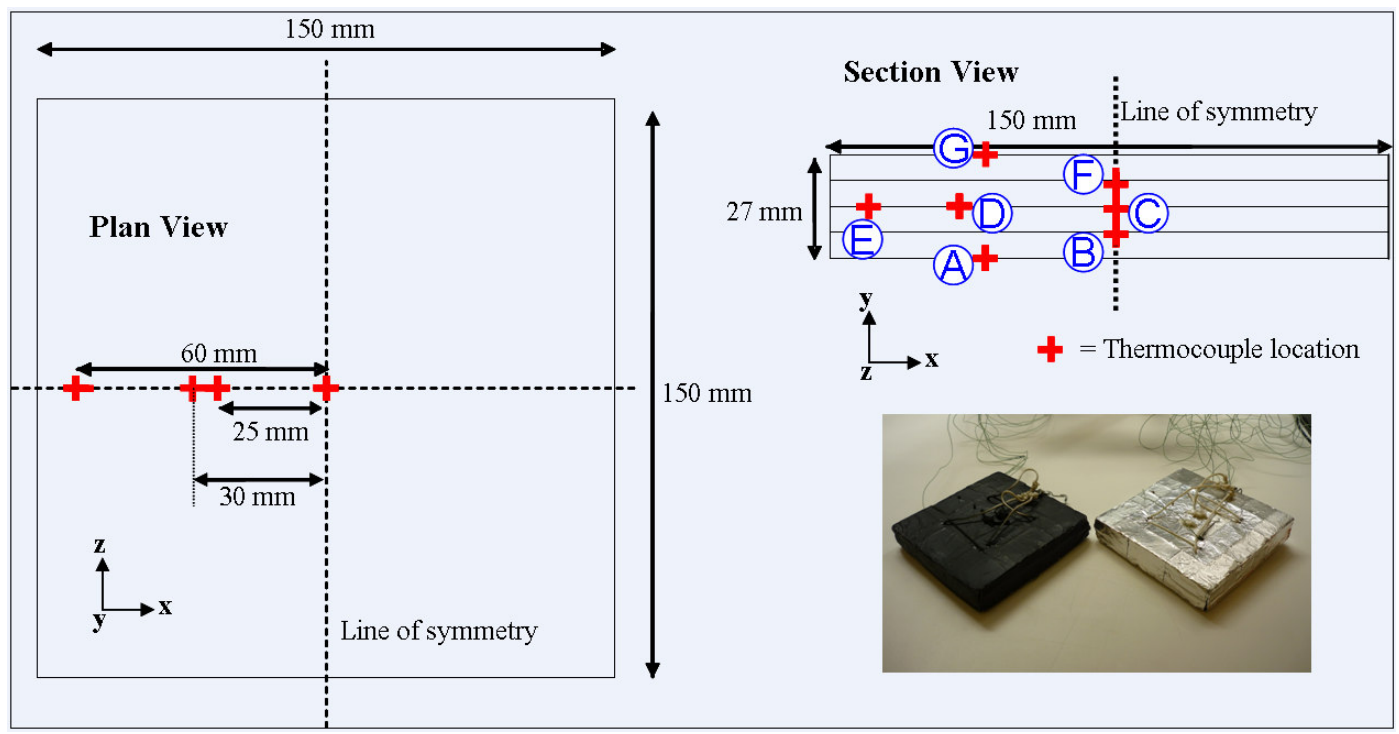

Fig. 1. Module dimensions and thermocouple locations. The section dimensions apply to all four sides of the panel. The plan dimensions apply to the top and bottom. Thermcouples are labeled A - G to allow identification of validation curves in section 3.1. The photo displays an example of the black-painted and aluminium covered modules.

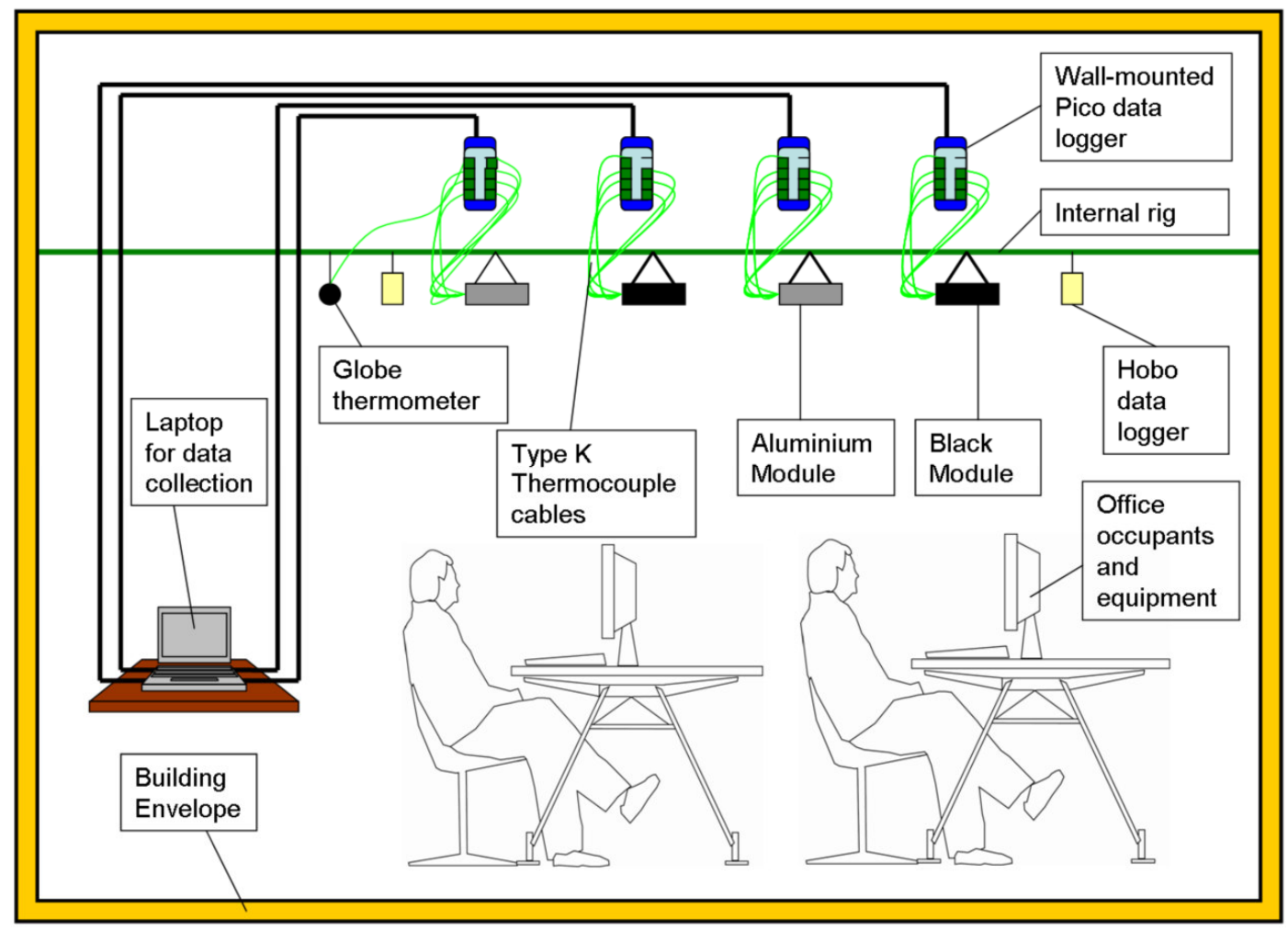

Fig. 2. The internal set up. Modules were placed between 0.25 and $0.5 \mathrm{~m}$ apart. This ensured similar local environmental conditions but negligible mutual interaction. 


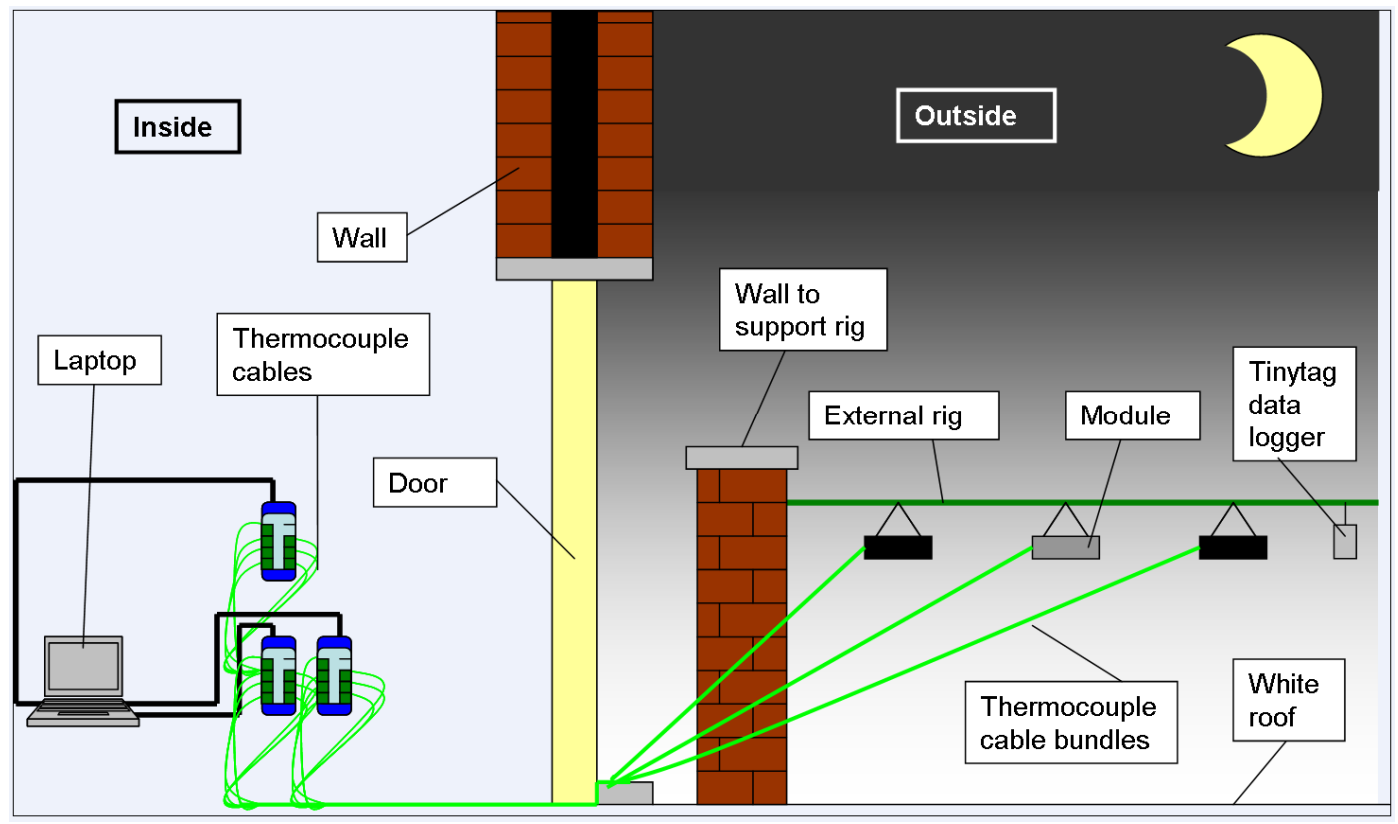

Fig. 3. The external set up. Modules given an equal view of the night sky and were placed between 0.25 and $0.5 \mathrm{~m}$ apart. This ensured similar local environmental conditions but negligible mutual interaction.

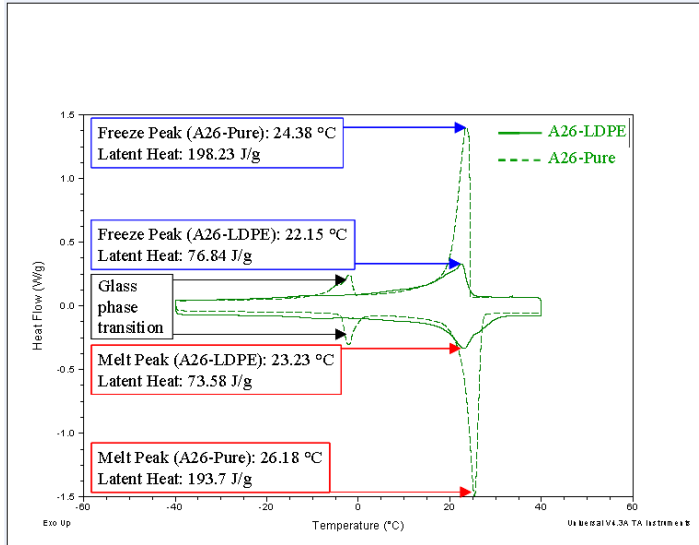

(a)

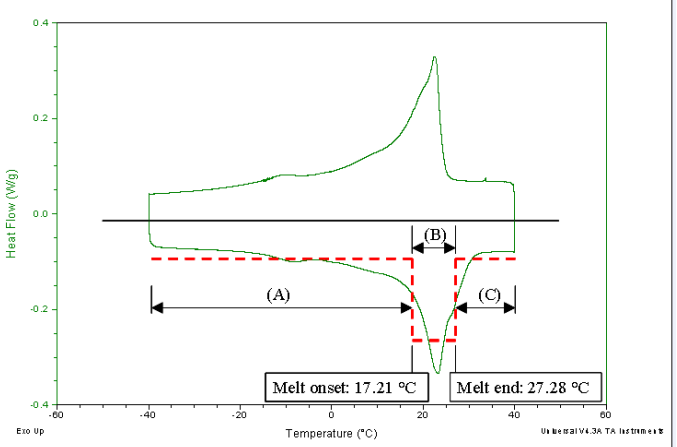

(b)

Fig. 4. (a) DSC curves of pure A26 paraffin and A26-LDPE composite. Peaks of melting and freezing are indicated along with melting and freezing latent heats. It may be observed that the presence of the LDPE scaffold has the effect of reducing the pure A26 peak and widening the phase transition zone. See Table. 1 for all thermophysical property figures of the A26-LDPE composite. (b) The DSC curve of the composite is displayed here with the dashed red line representing the variation in heat flow rate per unit mass with temperature change, as defined by the FLUENT model. Regions marked A and C are those in which sensible heating occurs. In region B sensible and latent heating occurs. 


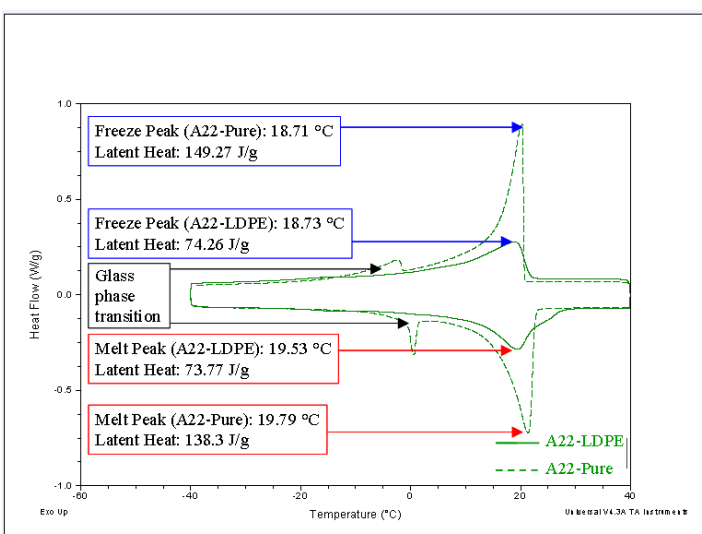

(a)

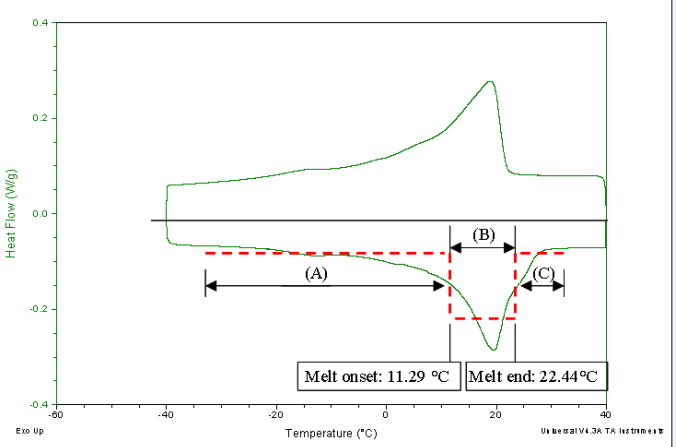

(b)

Fig. 5. (a) DSC curves of pure A22 paraffin and A22-LDPE composite. In all other respects the same as

Fig.4 - see Fig 4. caption. (b) The DSC curve of the A22-LDPE composite. In all other respects the same as Fig.4 - see Fig 4. caption.
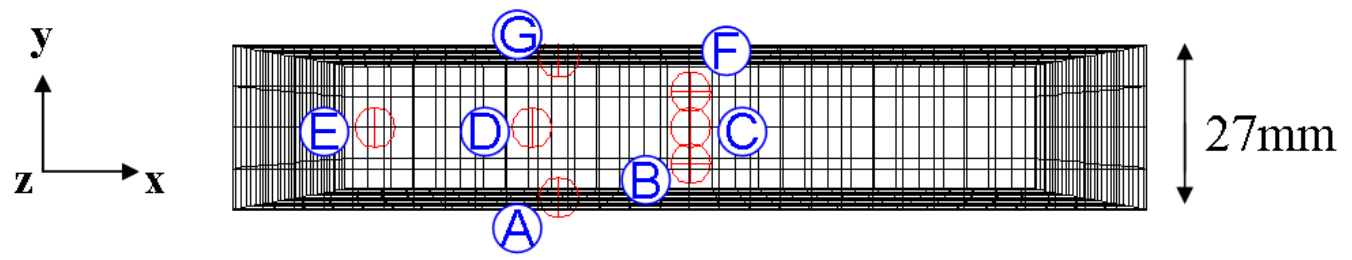

\section{(A)}

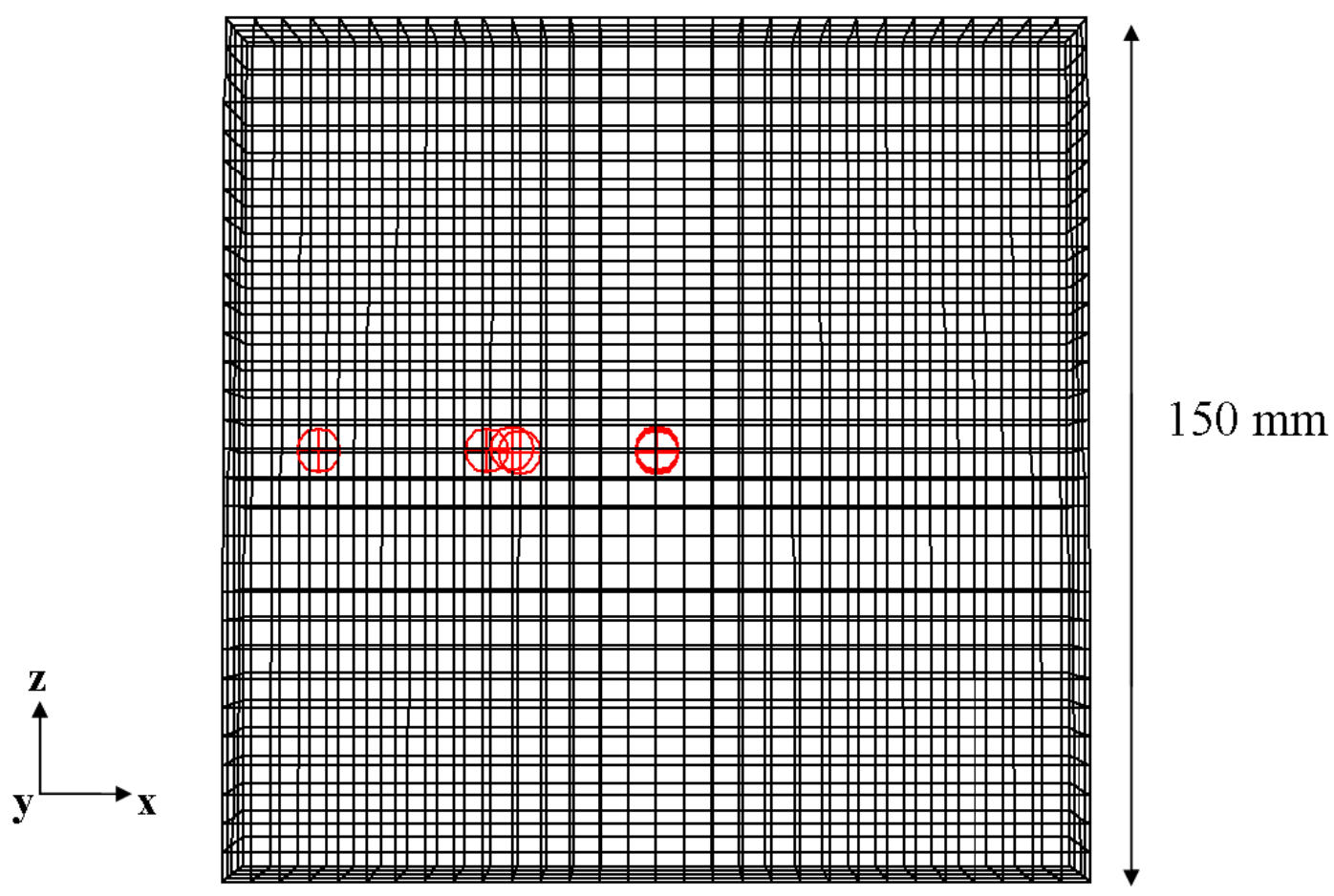

Fig. 6. FLUENT mesh of a panel with point surfaces labeled and located so as to correspond with thermocouples in the actual modules. 


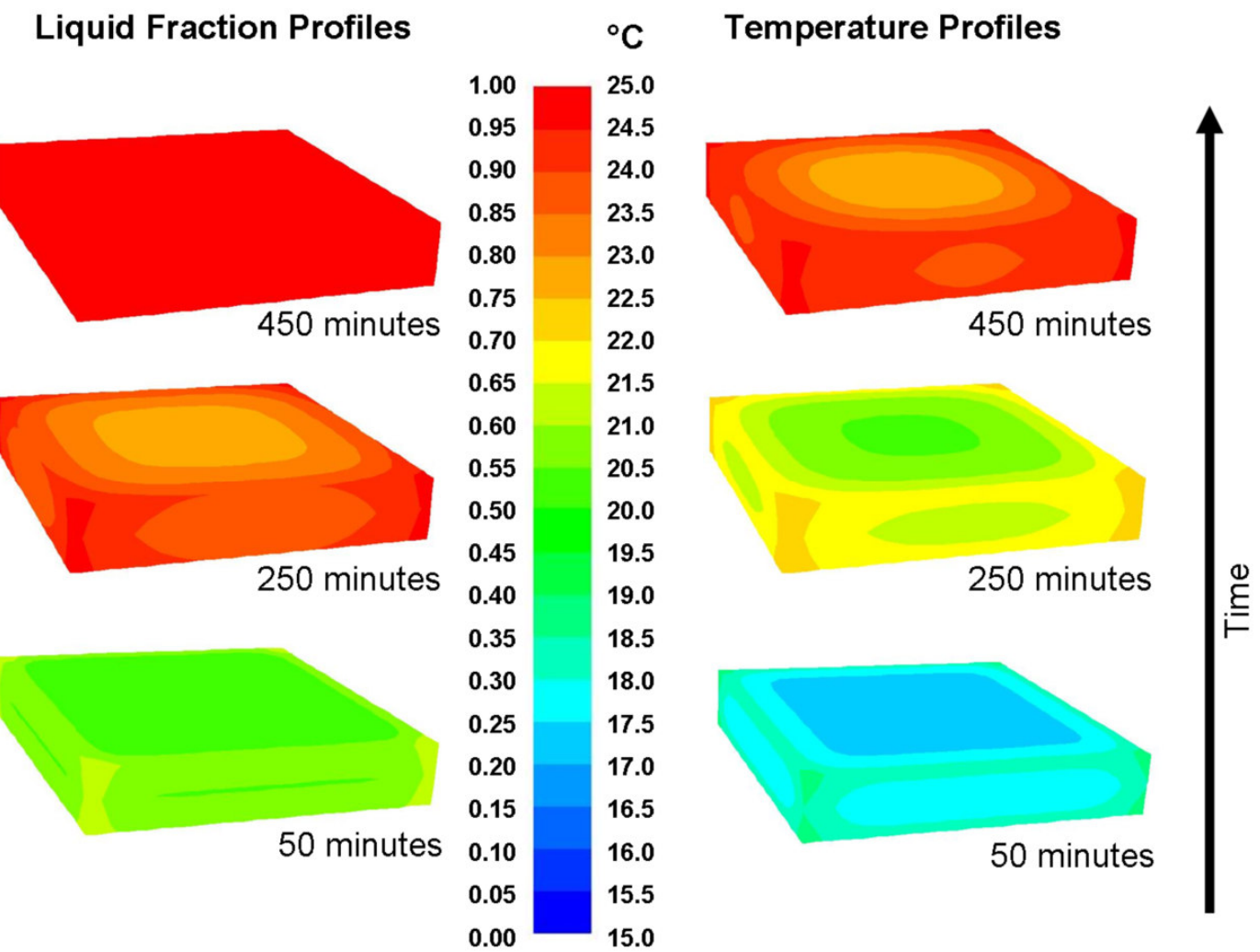

Fig. 7. Contours of temperature in the A22,A1,EC module at three stages of heating. The progression of heat from the corners and edges towards the centre can clearly be seen. At 450 minutes the module is entirely melted. The air temperature at this is $25.17^{\circ} \mathrm{C}$.
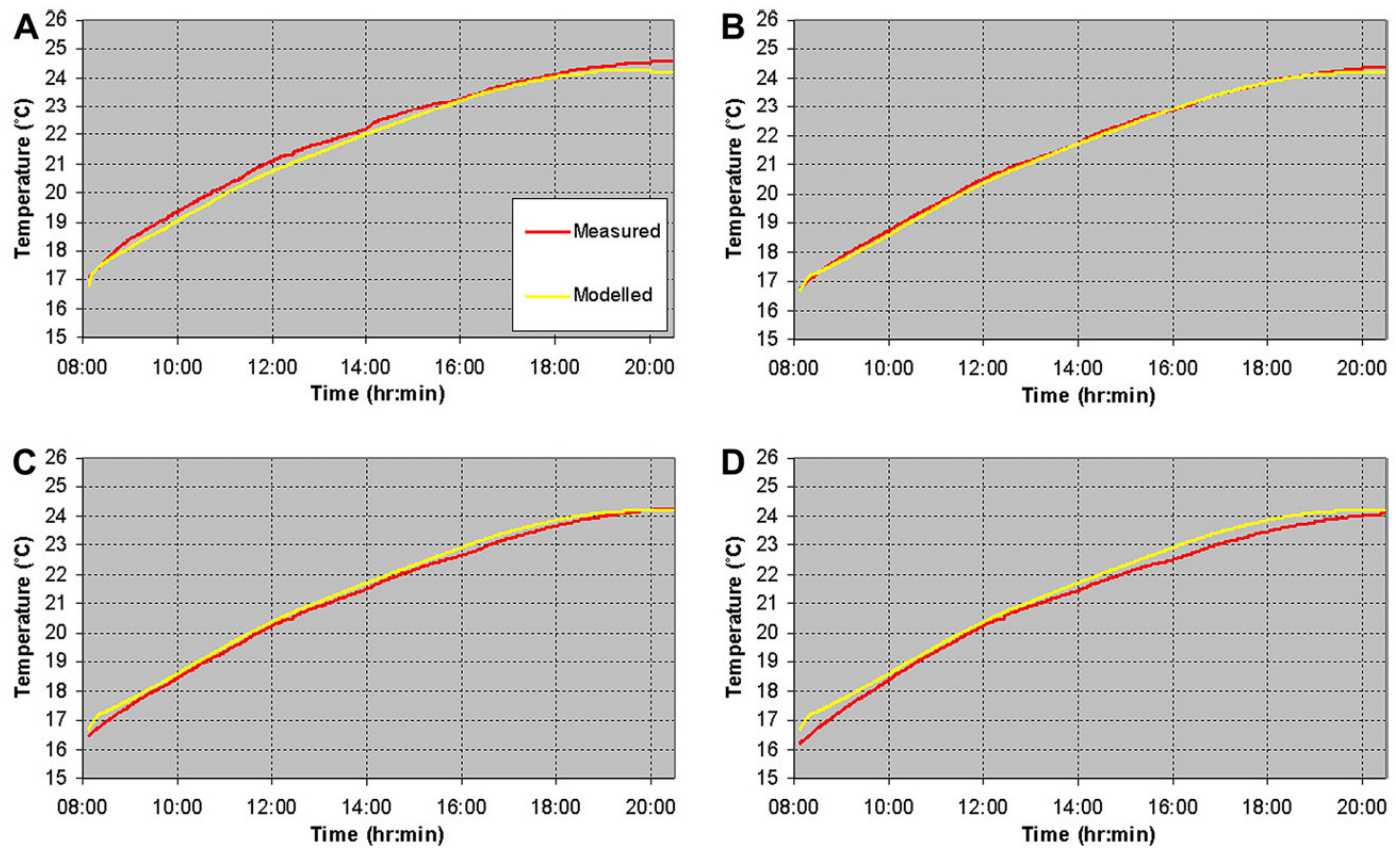

Fig. 8. Model validation for thermocouples A, B, C and D in the A26,Al,EC module. A convective heat transfer coefficient of $9 \mathrm{~W} / \mathrm{m}^{2} / \mathrm{K}$ was applied in the model for every 50 minute sub-period. 

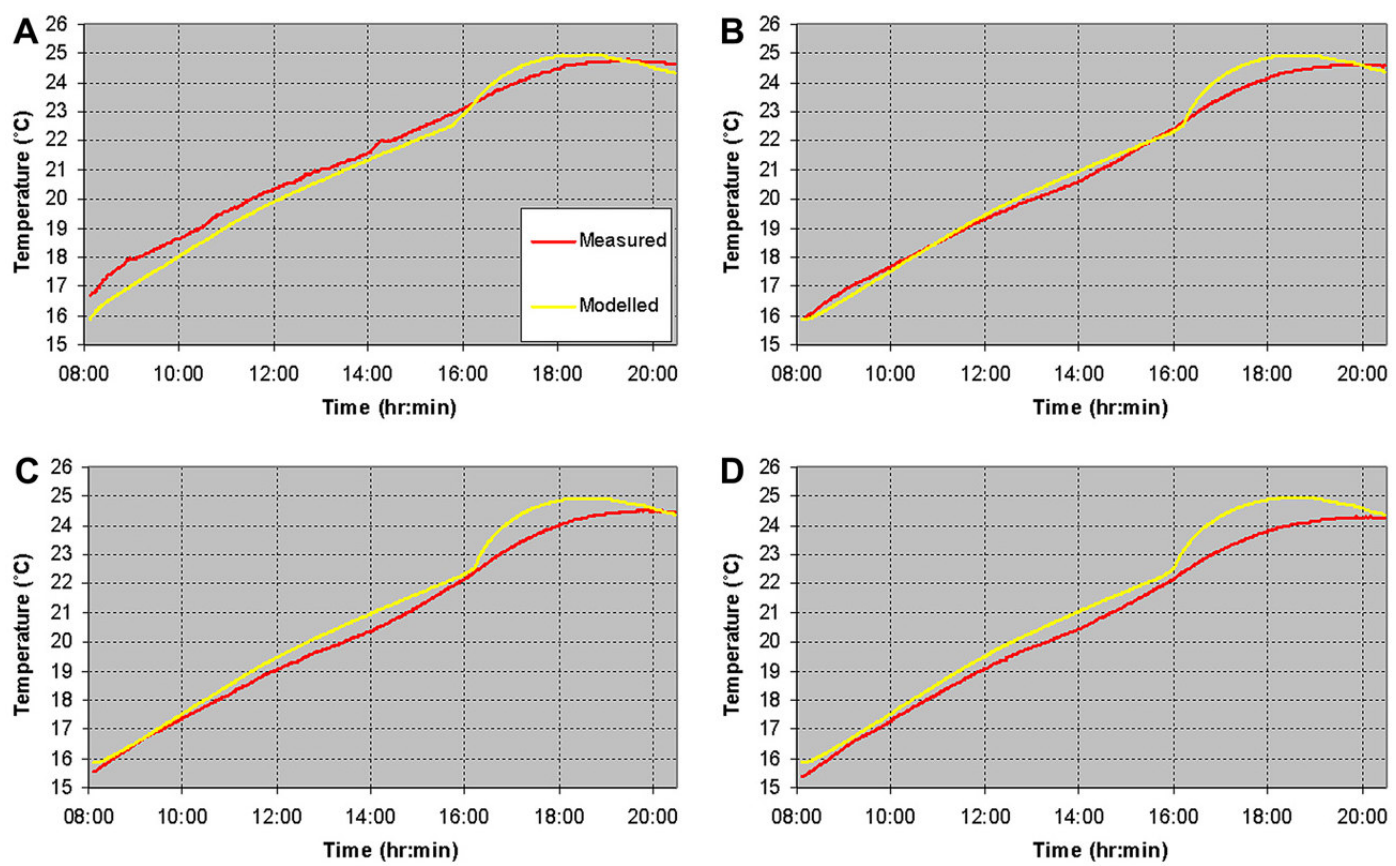

Fig. 9. Model validation for thermocouples A, B, C and D in the A22,A1,EC module. A convective heat transfer coefficient of $7 \mathrm{~W} / \mathrm{m}^{2} / \mathrm{K}$ was applied in the model for every 50 minute sub-period.
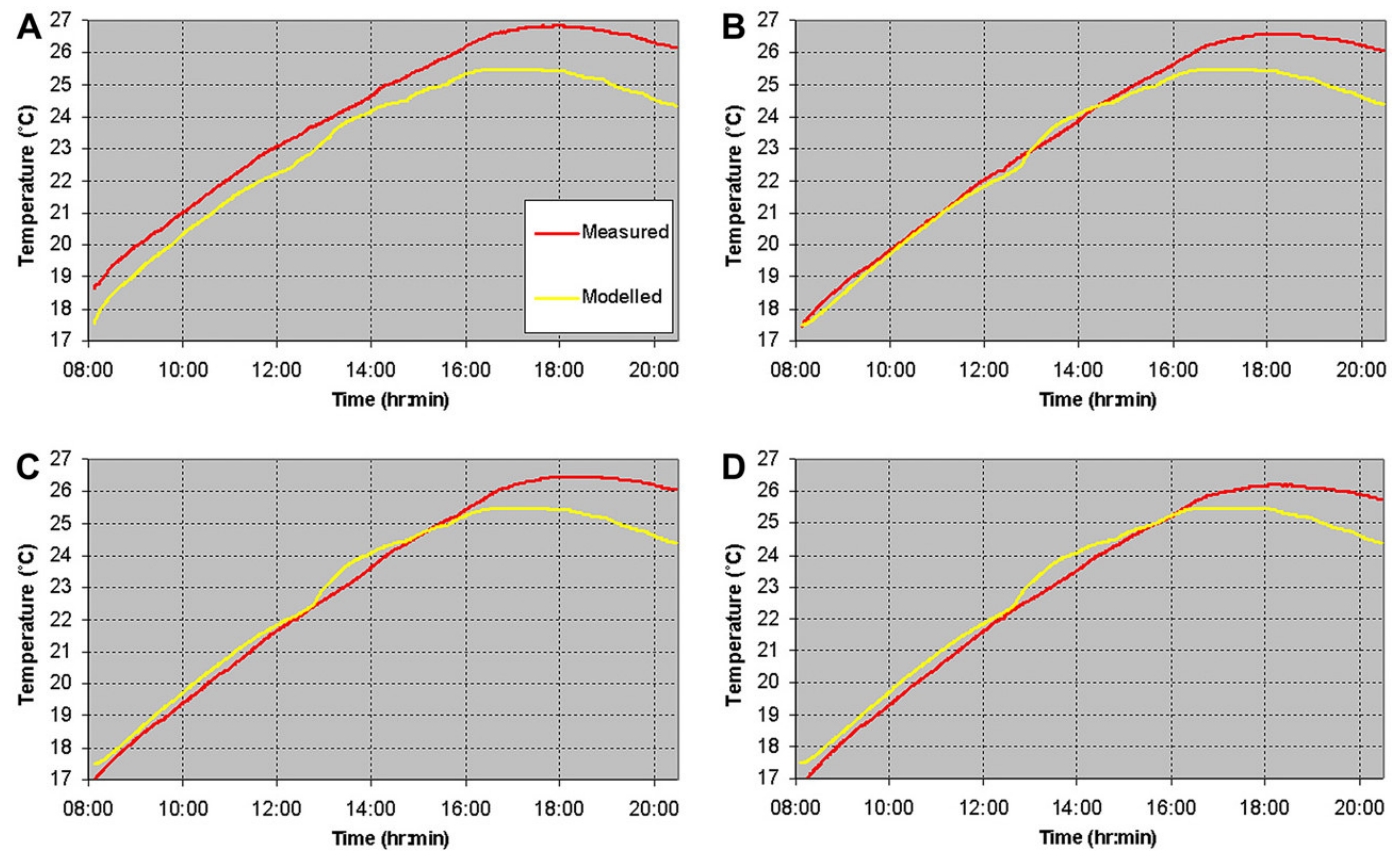

Fig. 10. Model validation for thermocouples A, B, C and D in the A22,B1,EC module. A convective heat transfer coefficient of $9 \mathrm{~W} / \mathrm{m}^{2} / \mathrm{K}$ was applied in the model for every 50 minute sub-period. 

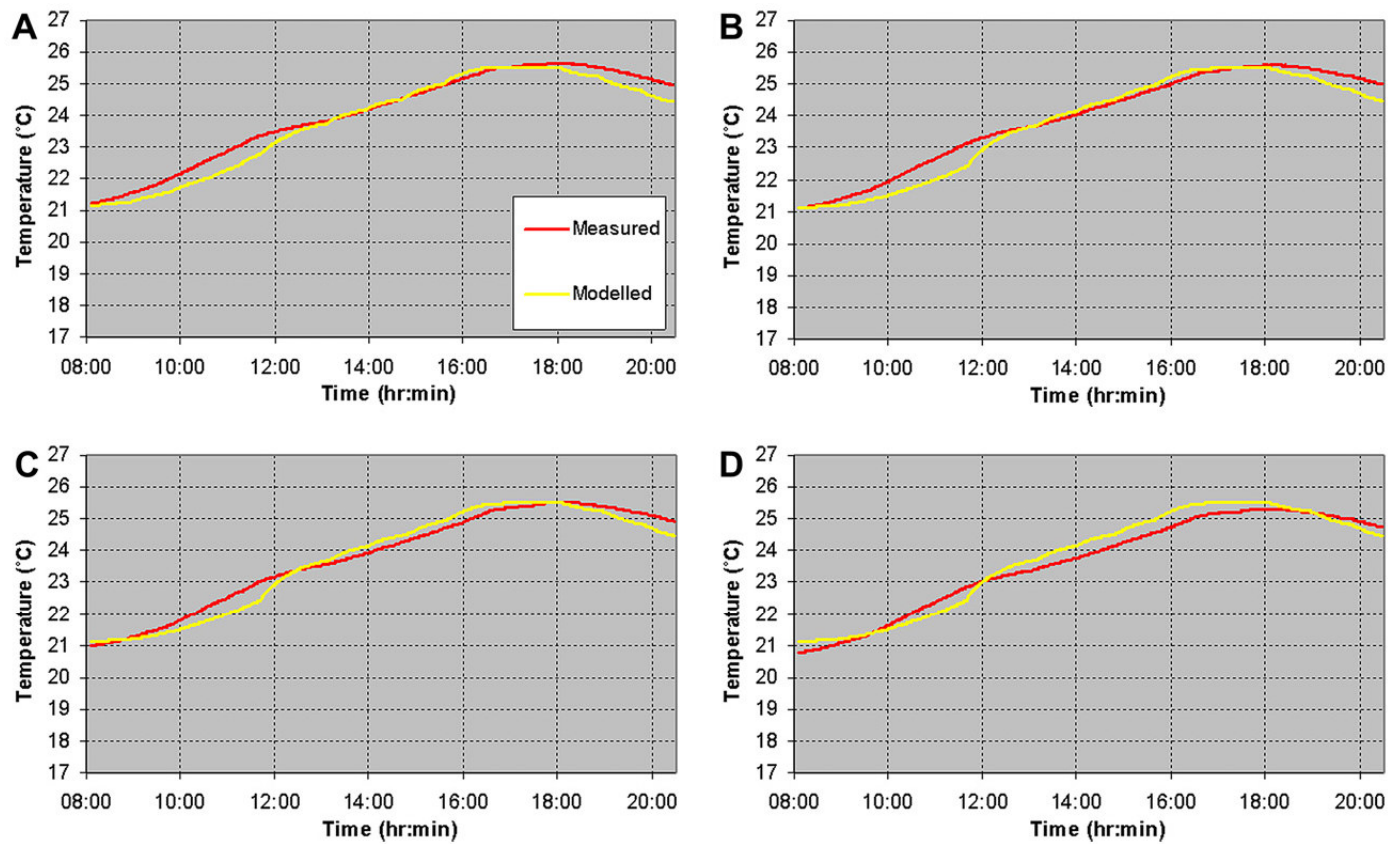

Fig. 11. Model validation for thermocouples A, B, C and D in the A22,B1,IC module. A convective heat transfer coefficient of $7 \mathrm{~W} / \mathrm{m}^{2} / \mathrm{K}$ was applied in the model for every 50 minute sub-period.

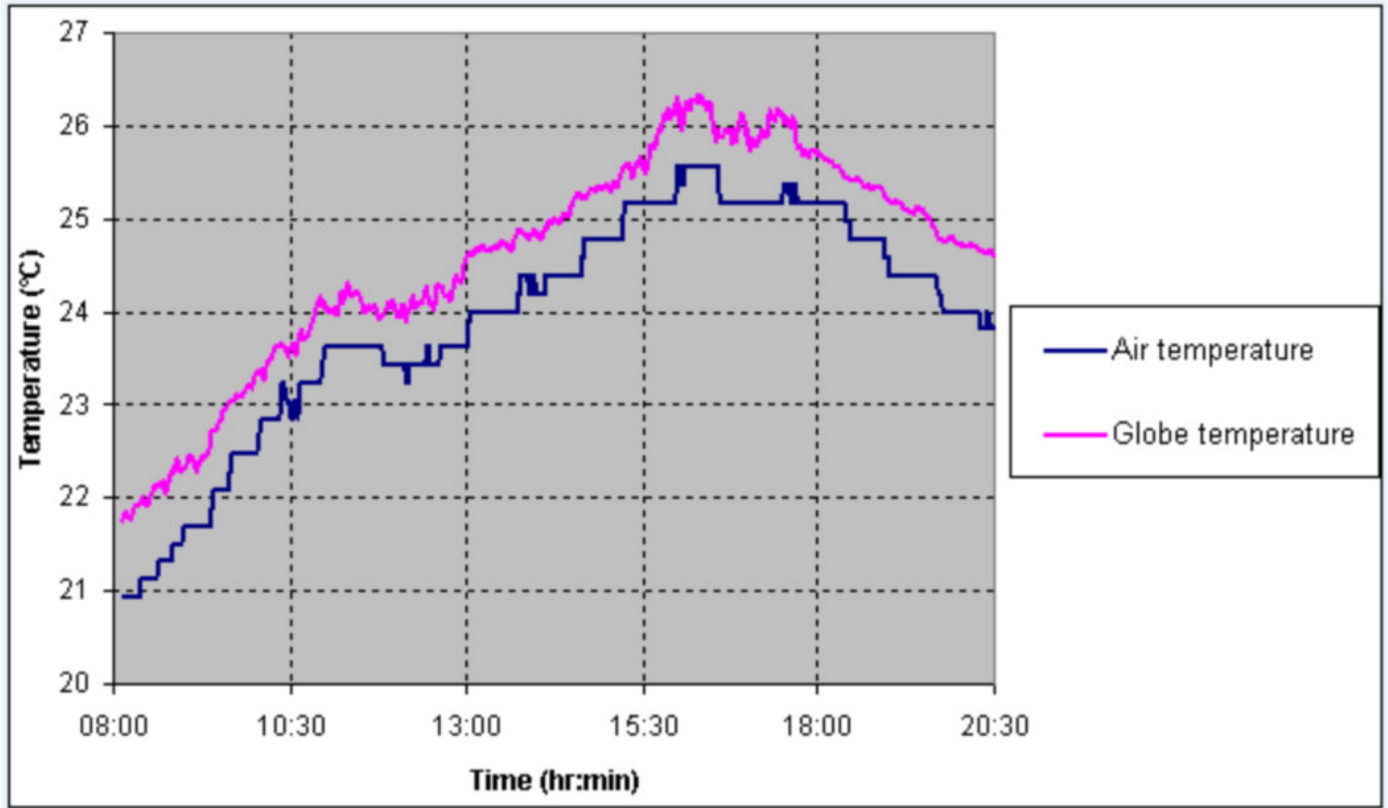

Fig. 12. Internal air and globe temperatures for the period 8:08am to 20:30pm. 


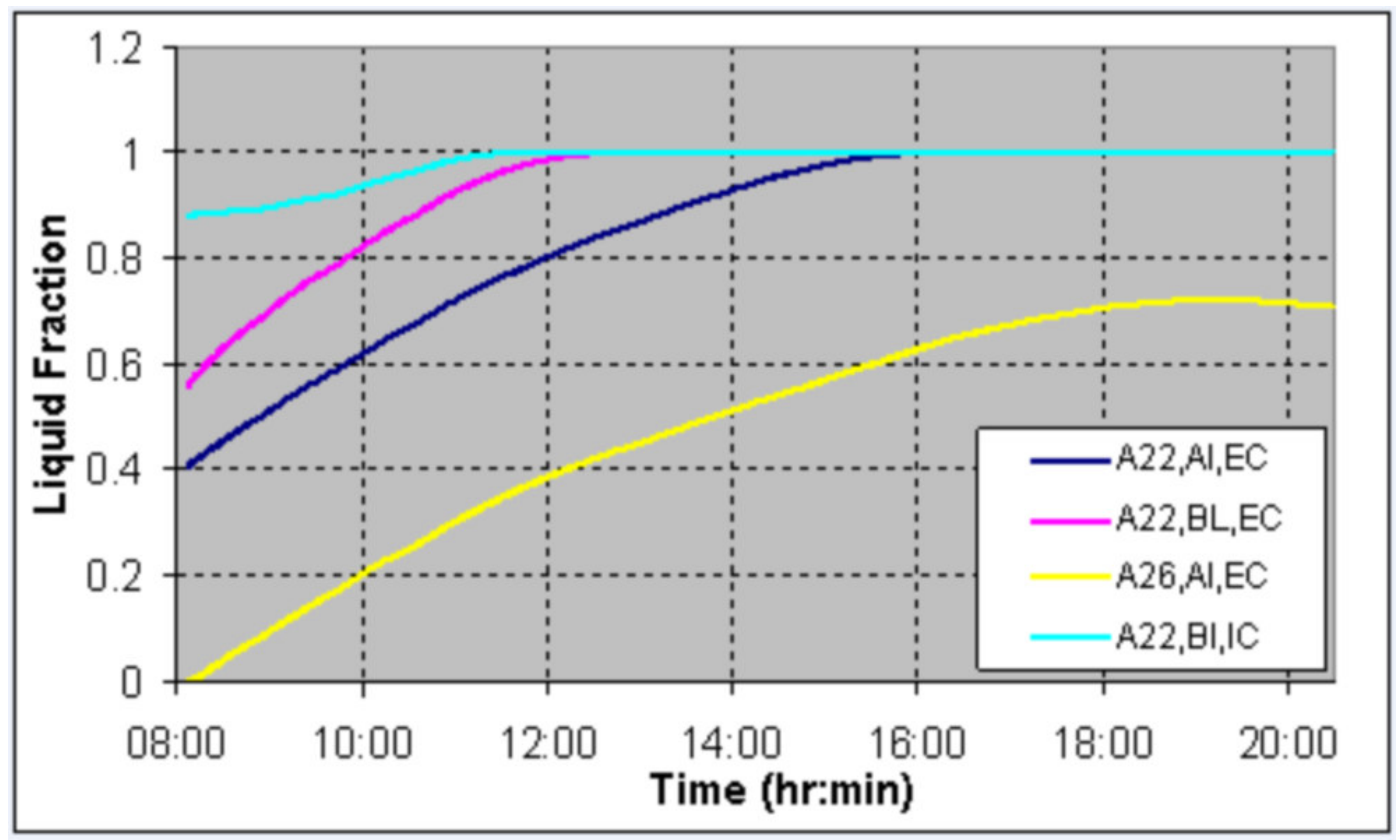

Fig. 13. Average liquid fraction profiles of the four modules.

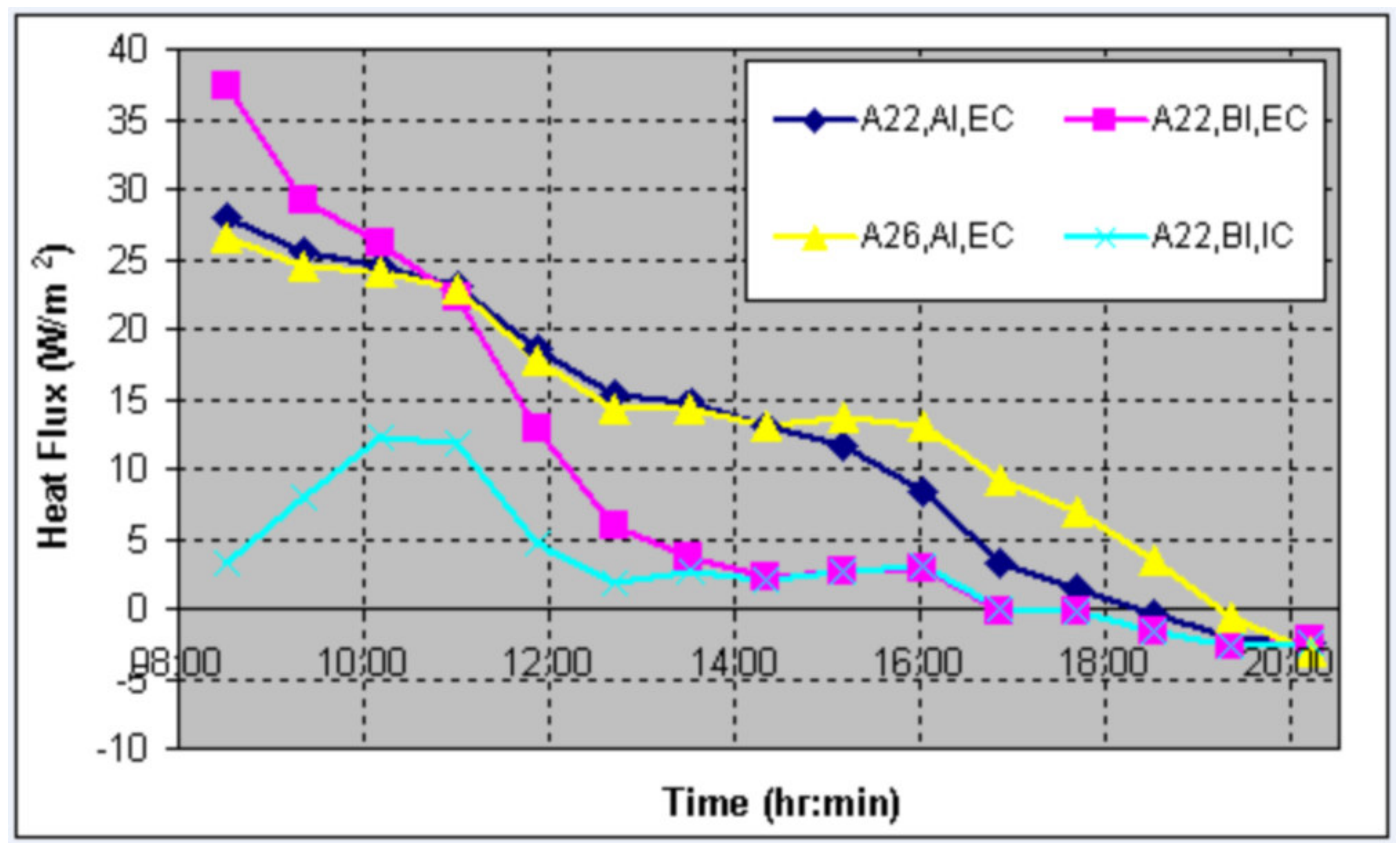

Fig. 14. Surface heat flux profiles of the four modules. Positive values indicate heat flow into the module. 


\section{TABLES}

Table 1 - Thermophysical properties of the tested PCM/LDPE composites.

\begin{tabular}{|l|c|c|}
\hline & A22 / LDPE - Composite & A26 / LDPE - Composite \\
\hline Density $\left(\mathrm{kg} / \mathrm{m}^{3}\right)$ & 852.7 & 834.4 \\
\hline Conductivity $(\mathrm{W} / \mathrm{m} / \mathrm{K})$ & 0.200 & 0.230 \\
\hline Specific Heat $(\mathrm{J} / \mathrm{g} / \mathrm{K})$ & 2.304 & 2.387 \\
\hline Latent Heat $(\mathrm{J} / \mathrm{g})$ & 74.02 & 75.21 \\
\hline Melt Onset Temperature $\left({ }^{\circ} \mathrm{C}\right)$ & 11.29 & 17.21 \\
\hline Melt Peak Temperature $\left({ }^{\circ} \mathrm{C}\right)$ & 19.53 & 23.23 \\
\hline Melt End Temperature $\left({ }^{\circ} \mathrm{C}\right)$ & 22.44 & 27.28 \\
\hline Freeze Onset Temperature $\left({ }^{\circ} \mathrm{C}\right)$ & 21.76 & 24.19 \\
\hline Freeze Peak Temperature $\left({ }^{\circ} \mathrm{C}\right)$ & 18.73 & 22.15 \\
\hline Freeze End Temperature $\left({ }^{\circ} \mathrm{C}\right)$ & 5.27 & 12.19 \\
\hline
\end{tabular}

